\title{
ANTESEDEN KEPUASAN PELANGGAN DAN DAMPAKNYA PADA NIAT PEMBELIAN ULANG
}

\author{
Zhafira Raihana ${ }^{1}$ \\ Putu Yudi Setiawan ${ }^{2}$ \\ ${ }^{1,2}$ Fakultas Ekonomi dan Bisnis Universitas Udayana, Bali, Indonesia \\ e-mail: zhafiraihana@yahoo.com
}

\begin{abstract}
ABSTRAK
Pada zaman ini, salah satu peluang bisnis adalah bisnis cafe. Penelitian ini bertujuan menjelasksan pengaruh suasana toko, kualitas pelayanan, dan kepuasan pelanggan terhadap niat pembelian ulang, serta peran kepuasan pelanggan memediasi pengaruh suasana toko dan kualitas pelayanan terhadap niat pembelian ulang. Penelitian ini dilakukan di The Night Market Cafe \& Co Working di Denpasar, dengan menggunakan 150 responden dan teknik analisis data berupa Path Analysis. Hasil dari penelitian ini menunjukkan bahwa suasana toko dan kualitas pelayanan memiliki pengaruh positif dan signifikan terhadap kepuasan pelanggan. Suasana dan kualitas pelayanan memiliki pengaruh positif dan signifikan terhadap niat pembelian ulang. Kepuasan pelanggan memiliki pengaruh positif dan signifikan terhadap niat pembelian ulang. Selain itu, hasil penelitian ini juga menunjukkan bahwa kepuasan pelanggan mampu memediasi pengaruh suasana toko dan kualitas pelayanan terhadap niat pembelian ulang di The Night Market Cafe \& Co Working.
\end{abstract}

Kata Kunci: suasana toko, kualitas pelayanan, kepuasan pelanggan, niat pembelian ulang

\begin{abstract}
In this era, one of the business opportunity is cafe business. This study aims to explain the effect of store atmosphere, service quality, and customer satisfaction on repurchase intentions, and the role of customer satisfaction mediates the influence of store atmosphere and service quality on repurchase intentions. The research was conducted at The Night Market Cafe \& Co Working in Denpasar, using 150 respondents and data analysis techniques in the form of Path Analysis. The results of this study indicate that the store atmosphere and service quality have a positive and significant impact on customer satisfaction. The atmosphere and quality of service have a positive and significant influence on repurchase intention. Customer satisfaction has a positive and significant impact on repurchase intentions. In addition, the results of this study also show that customer satisfaction is able to mediate the effect of store atmosphere and service quality on repurchase intention at The Night Market Cafe \& Co Working
\end{abstract}

Keywords: shop atmosphere, service quality, customer satisfaction, repurchase intention 


\section{PENDAHULUAN}

Pada zaman yang kian berkembang pesat ini, dunia bisnis turut berkembang. Para pelaku bisnis berlomba-lomba untuk menyajikan sesuatu yang berbeda dari pesaingnya dalam memenuhi kebutuhan konsumen. Salah satu bisnis yang terus menjadi peluang dan semakin digandrungi adalah bisnis cafe. Menghadapi persaingan yang kian ketat tersebut, pebisnis cafe harus pandai melihat fenomena yang sedang marak di lingkungan sekitar dan memperhatikan hal apa yang diinginkan calon konsumen agar bisnis cafe tersebut dapat lebih unggul dari pesaing yang memiliki bisnis sejenis.

Fenomena saat ini, menunjukkan bahwa gaya hidup masyarakat yang cenderung mengikuti trend. Tidak hanya dikalangan anak muda saja, namun orang tua pun juga berusaha mengikuti trend yang sedang marak terjadi. Hal tersebut terjadi pula pada pemilihan tempat makan di luar rumah. Dewasa ini masyarakat lebih memilih untuk makan di luar rumah daripada di rumah. Keputusan konsumen dalam memilih tempat makan, tidak hanya didasarkan pada varian menu dan cita rasanya saja, melainkan dari segi suasana. Suasana yang unik dan nyaman memiliki nilai tersendiri bagi konsumen. Apalagi melihat trend zaman sekarang, dimana masyarakat mencari suasana atau tempat menarik yang dapat di gunakan untuk berfoto, dan setelah itu hasil foto tersebut dapat di share ke social media yang dapat membuat para pengguna social media lain bertanya dan turut ingin untuk mengunjungi tempat tersebut.

Di pusat Kota Denpasar terdapat salah satu cafe yang menyuguhkan pemandangan yang segar, yaitu The Night Market Cafe \& Co Working. Dengan 
mengusung konsep piknik, pengunjung dapat bersantai menikmati hidangan dan suasana nyaman dengan bean bag sebagai tempat duduk di bawah bintang-bintang dan pepohonan hijau. Selain itu, The Night Market Cafe \& Co Working juga menyediakan ruangan dilantai dua dengan fasilitas sofa, air conditioner, serta free wifi. Pengunjung di The Night Market Café \& Co Working cukup beragam, dari remaja SMA, mahasiswa, pegawai kantor, serta keluarga yang datang untuk bersantai dan bersantap makanan bersama.

Menurut hasil pra survei yang dilakukan berupa wawancara tidak terstruktur pada 10 pengunjung di The Night Market Café \& Co Working menunjukkan 6 diantaranya merasa puas dan memiliki niat pembelian ulang ke The Night Market Café \& Co Working. Namun, para pengunjung tersebut juga menyampaikan keluhan-keluhan yang dirasakan.

\section{Tabel 1.}

Daftar Keluhan yang Disampaikan Pengunjung The Night Market Café \& Co Working

\begin{tabular}{cl}
\hline No. & \multicolumn{1}{c}{ Keluhan } \\
\hline 1. & Variasi menu yang kurang beragam \\
2. & Tempat parkir yang kurang luas \\
3. & Kurang tersedianya permainan yang bisa dipinjam oleh pengunjung (catur, karambol, \\
4. & Ruangan tertutup yang kurang luas \\
\hline
\end{tabular}
Sumber : Data Primer, 2017

Daftar keluhan yang ditunjukkan pada Tabel 1 diatas menjadi bahan evaluasi bagi pengelola usaha The Night Market Café \& Co Working untuk lebih memperhatikan suasana toko dan kualitas pelayanan agar pengunjung merasa puas. Gonius (2013) menyatakan bahwa keluhan tidak dapat dihindari oleh perusahaan, yang bergerak dibidang jasa karena memberikan pelayanan yang terbaik tidaklah mudah. 
Bagi para pelaku usaha yang bergerak dibidang kuliner, kualitas pelayanan merupakan variabel yang sangat penting dalam proses keputusan pembelian karena pelayanan yang memuaskan pelanggan berdampak pada terjadinya pembelian berulang-ulang yang pada akhirnya meningkatkan penjualan (Suaridewi, 2016). Niat pembelian ulang merupakan minat pembelian yang didasarkan atas pengalaman pembelian yang telah dilakukan di masa lalu (Faradisa, 2016). Niat beli ulang tercipta karena pelanggan merasa kualitas produk dan kualitas pelayanan yang diberikan sesuai dengan apa yang diharapkan sehingga pelanggan akan berniat untuk membeli produk yang sama di waktu selanjutnya (Faradiba, 2013).

Kepuasan pelanggan adalah perasaan yang terjadi pada pelanggan setelah menyelesaikan pembelian dalam fase setelah akuisisi pelayanan (Seni'c, 2013). Jika pelanggan percaya bahwa kinerja sebuah pelayanan lebih baik daripada yang mereka harapkan, mereka yakin puas (Allameh et al., 2015). Pratminingsih, dkk (2014) menyatakan bahwa kepuasan terjadi ketika penyedia pelayanan memenuhi harapan dan norma pelanggan. Jika kinerja produk kurang dari yang diharapkan itu, pembelinya tidak puas. Selain itu, banyak penelitian telah mengidentifikasi kepuasan pelanggan sebagai penentu penting dari niat membeli kembali (Tu et al., 2012).

Salah satu hal yang dapat menciptakan kepuasan bagi pelanggan adalah suasana toko. Suasana toko (store atmosphere) adalah suasana yang memiliki efek terukur pada faktor emosional seperti kesenangan dan gairah, yang pada gilirannya dapat mempengaruhi waktu dan uang yang dihabiskan di toko 
(Ballantine et al., 2015). Marinkovic et al. (2014) menyatakan bahwa suasana memiliki dampak yang signifikan terhadap niat mengunjungi kembali pada pengunjung di empat restoran layanan penuh di Serbia. Hal ini didukung pula oleh Angger dan Rubiyanti (2015) yang menyatakan bahwa store atmosphere berpengaruh positif dan signifikan terhadap minat pembelian ulang pada Jigoku Ramen di Bandung.

Faktor penting lainnya yang mendorong kepuasan adalah kualitas layanan. Kualitas pelayanan adalah hal paling penting yang harus diperhatikan oleh perusahaan, karena kepuasan dan loyalitas pelanggan sangat dipengaruhi oleh kualitas layanan yang baik (Qin dan Prybutok, 2009). Menurut Heryani (2014), kualitas pelayanan berpengaruh positif tehadap pembelian ulang yang dimediasi oleh kepuasan pelanggan pada pelanggan Bengkel Andoyo Motor di Yogyakarta, namun Destanti (2010) menyatakan kualitas pelayanan berpengaruh positif tidak signifikan terhadap niat pembelian ulang pada jasa salon dan jasa Internet Service Provider (ISP) di Yogyakarta.

Berdasarkan dari uraian latar belakang diatas, maka diperlukan suatu penelitian lebih lanjut yang berhubungan dengan variabel-variabel tersebut. Penelitian ini diharapkan dapat menjawab hipotesis serta dapat dirasakan manfaatnya bagi pihak-pihak yang membutuhkan. Keterbaharuan dari peneitian ini adalah menggabungkan beberapa variabel dari penelitian sebelumnya menjadi satu kerangka konsep yang terintegrasi.

Penelitian ini dilakukan dengan tujuh tujuan diantaranya untuk menjelaskan pengaruh suasana toko terhadap kepuasan pelanggan pada The Night Market Cafe 
\& Co Working di Denpasar; untuk menjelaskan pengaruh kualitas pelayanan terhadap kepuasan pelanggan pada The Night Market Cafe \& Co Working di Denpasar; untuk menjelaskan pengaruh suasana toko terhadap niat pembelian ulang pada The Night Market Cafe \& Co Working di Denpasar; untuk menjelaskan pengaruh kualitas pelayanan terhadap niat pembelian ulang pada The Night Market Cafe \& Co Working di Denpasar; untuk menjelaskan pengaruh kepuasan pelanggan terhadap niat pembelian ulang pada The Night Market Cafe \& Co Working di Denpasar; untuk menjelaskan pengaruh suasana toko terhadap niat pembelian ulang melalui mediasi kepuasan pelanggan pada The Night Market Cafe \& Co Working di Denpasar; serta untuk menjelaskan pengaruh kualitas pelayanan terhadap niat pembelian ulang melalui mediasi kepuasan pelanggan pada The Night Market Cafe \& Co Working di Denpasar.

Atmosfir toko merupakan salah satu hal yang penting untuk diperhatikan oleh pelaku usaha untuk dapat menarik minat beli calon konsumen. Menurut Kotler dan Keller (2012:62) mengenai suasana toko yaitu : "Suasana toko (store atmosphere) adalah suasana terencana yang sesuai dengan pasar sasarannya dan yang dapat menarik pelanggan untuk membeli." Hasil penelitian yang dilakukan oleh Tendean (2015) menyatakan bahwa store atmosphere berpengaruh secara positif dan signifikan terhadap kepuasan pelanggan. Begitu juga dengan Tulipa et al. (2014) dan Kristiana (2017) yang menyatakan store atmosphere berpengaruh secara positif terhadap kepuasan pelanggan, memiliki arti bahwa semakin menarik suasana toko yang diberikan maka akan dapat meningkatkan kepuasan pada 
pelanggan. Berdasarkan hasil penelitian tersebut dapat dikemukakan hipotesis sebagai berikut:

\section{$\mathrm{H}_{1}$ : Suasana Toko Berpengaruh Positif dan Signifikan Terhadap Kepuasan Pelanggan.}

Baik buruknya kualitas pelayanan bergantung pada kemampuan penyedia layanan memenuhi harapan pelanggan secara konsisten (Adixio, 2013). Menurut Kotler (2012), service quality dibangun atas adanya perbandingan dua faktor utama yaitu persepsi pelanggan atas pelayanan yang nyata mereka terima (perceived service) dengan pelayanan yang sesungguhnya diharapkan atau diinginkan (expected service). Jika perceived service melebihi expected service, maka kualitas jasa dipersepsikan sebagai kualitas ideal. Sebaliknya apabila perceived service lebih jelek dibandingkan expected service, maka kualitas jasa dipersepsikan negatif atau buruk. Hasil penelitian yang dilakukan oleh Heryani (2014) menyatakan bahwa terdapat pengaruh yang positif dan signifikan antara kualitas pelayanan terhadap kepuasan pelanggan. Hal serupa diperoleh dalam penelitian Yunus (2014) dan Budiarti (2013) yang sama-sama menyatakan bahwa semakin tinggi kualitas pelayanan yang diberikan maka akan meningkatkan kepuasan pelanggan. Berdasarkan hasil penelitian tersebut dapat dikemukakan hipotesis sebagai berikut:

\section{$\mathrm{H}_{2}$ : Kualitas Pelayanan Berpengaruh Positif dan Signifikan Terhadap Kepuasan Pelanggan.}

Sinaga dkk. (2012) menyatakan bahwa store atmosphere yang dirancang dengan baik dan sesuai dengan target pasar yang ditetapkan akan mampu menciptakan emosi-emosi yang kondusif dalam berbelanja. Store atmosphere 
berpengaruh secara signifikan terhadap minat pembelian ulang (Angger dan Rubiyanti, 2015). Store atmosphere diciptakan dengan baik dan menarik dapat meningkatkan niat beli ulang (repurchase intention) pada pelanggan (Tulipa et al., 2014; Triani, 2013). Berdasarkan hasil penelitian tersebut dapat dikemukakan hipotesis sebagai berikut:

$\mathrm{H}_{3}$ : Suasana Toko Berpengaruh Positif dan Signifikan Terhadap Niat Pembelian Ulang.

Perusahaan harus menciptakan kualitas pelayanan terbaik yang diinginkan oleh pelanggan agar dapat menimbulkan kepuasan dan mendorong niat pembelian ulang. Kualitas pelayanan berpengaruh positif dan signifikan terhadap niat pembelian kembali (Rizqulloh, 2015; Adixio dan Saleh, 2013; Aryadhe dan Rastini, 2016). Namun berlawanan dengan hasil penelitian Destanti (2010) yang menyatakan kualitas pelayanan berpengaruh positif tidak signifikan terhadap niat pembelian ulang, yang berati semakin tinggi kualitas pelayanan yang dirasakan pelanggan, semakin tinggi pula niat pembelian ulang pelanggan tersebut. Peningkatan kualitas pelayanan hanya memberikan pengaruh yang kecil terhadap niat pembelian ulang. Berdasarkan hasil penelitian tersebut dapat dikemukakan hipotesis sebagai berikut:

\section{$\mathrm{H}_{4}$ : Kualitas Pelayanan Berpengaruh Positif dan Signifikan Terhadap Niat} Pembelian Ulang.

Kepuasan adalah perasaan yang terjadi pada pelanggan setelah menyelesaikan pembelian dalam fase setelah akuisisi pelayanan (Seni'c, 2013). Kepuasan pelanggan adalah konsep kunci dibidang pemasaran dan manajemen, 
terutama di industri jasa (Heung and $\mathrm{Gu}, 2012$ ). Kepuasan pelanggan merupakan hal yang krusial dalam menentukan suksesnya suatu bisnis (Anita dan Gede, 2015).

Kepuasan pelanggan berpengaruh signifikan dalam meningkatkan niat beli ulang (Palma dan Andjarwati, 2016). Didukung oleh hasil penelitian Puspitasari (2011) dan Yan et al. (2015) bahwa terdapat pengaruh yang signifikan dari kepuasan pelanggan terhadap niat beli ulang pada pelanggan. Berdasarkan hasil penelitian tersebut dapat dikemukakan hipotesis sebagai berikut:

$\mathrm{H}_{5}$ : Kepuasan Pelanggan Berpengaruh Positif dan Signifikan Terhadap Niat Pembelian Ulang.

Suasana toko yang mengesankan dapat meningkatkan tingkat kepuasan pelanggan dan pengalaman membeli (Hussain dan Ali, 2015), serta akan dapat memberikan motivasi bagi pelanggan untuk datang kembali dan melakukan pembelian ulang (repeat buying). Hasil penelitian yang dilakukan oleh Heryani (2014) menyatakan bahwa semakin tinggi atau semakin nyaman store atmosphere yang diberikan kepada pelanggan akan memberikan kepuasan kepada pelanggan dan akan meningkatkan pembelian ulang Berdasarkan hasil penelitian tersebut dapat dikemukakan hipotesis sebagai berikut:

\section{$\mathrm{H}_{6}$ : Kepuasan Pelanggan Memediasi Suasana Toko Terhadap Niat Pembelian} Ulang.

Di saat suatu perusahaan berhasil membuat pelanggannya merasa puas dengan kualitas pelayanan yang telah diberikan, maka kualitas pelayanan yang baik tersebut akan memberikan dorongan pula kepada pelanggan untuk melakukan pembelian ulang (repurchase) di layanan jasa tersebut. Adixio dan 
Saleh (2013) menyatakan bahwa kualitas pelayanan berpengaruh signifikan positif terhadap niat pembelian ulang melalui mediasi kepuasan pelanggan. Berdasarkan hasil penelitian tersebut dapat dikemukakan hipotesis sebagai berikut:

$\mathrm{H}_{7}$ : Kepuasan Pelanggan Memediasi Kualitas Pelayanan Terhadap Niat Pembelian Ulang.

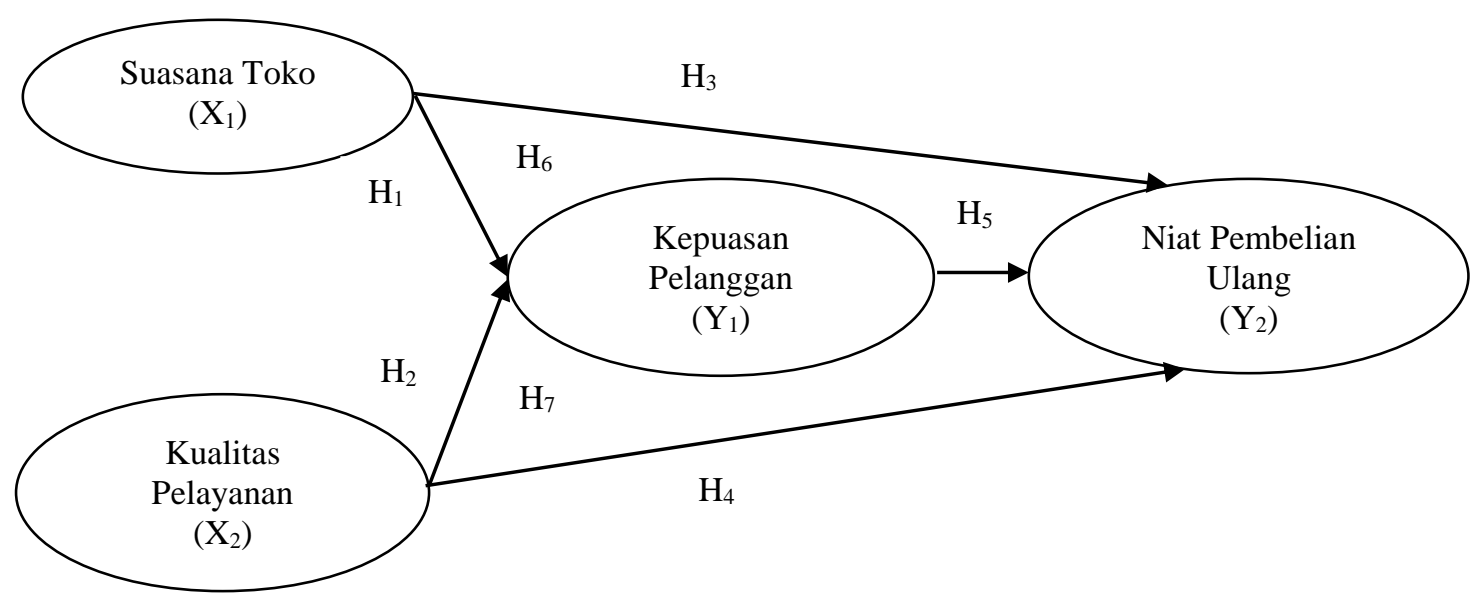

Gambar 1. Kerangka Konsep Penelitian

Sumber: Marinkovic et al. (2014),Adixio dan Saleh (2013)

\section{METODE PENELITIAN}

Penelitian ini menggunakan pendekatan kuantitatif dan termasuk kedalam penelitian yang bersifat asosiatif, karena penilitian ini bertujuan untuk menguji hubungan antara variabel suasana toko dan variabel kualitas pelayanan terhadap niat pembelian ulang yang dimediasi oleh kepuasan pelanggan di The Night Market Cafe \& Co Working di Denpasar. Penelitian ini dilakukan di The Night Market Cafe \& Co Working yang berada di Kota Denpasar.

Objek penelitian ini adalah suasana toko, kualitas pelayanan, kepuasan pelanggan, dan niat pembelian ulang. Variabel bebas atau eksogen dalam 
penelitian ini adalah suasana toko yang disimbolkan dengan (X1) dan kualitas pelayanan yang disimbolkan dengan (X2). Variabel terikat atau endogen dalam penelitian ini adalah kepuasan pelanggan yang disimbolkan dengan (Y1) dan niat pembelian ulang yang disimbolkan dengan (Y2).

Tabel 2.

Indikator

\begin{tabular}{|c|c|c|c|c|}
\hline \multicolumn{3}{|c|}{ Variabel Penelitian } & Indikator & Referensi \\
\hline \multirow[b]{2}{*}{ Eksogen } & $\begin{array}{l}\text { Suasana Toko } \\
\quad\left(\mathrm{X}_{1}\right)\end{array}$ & $\begin{array}{l}\text { 1) } \\
\text { 2) } \\
\text { 3) }\end{array}$ & $\begin{array}{l}\text { Layout } \\
\text { Musik } \\
\text { Desain Bangunan }\end{array}$ & $\begin{array}{c}\text { Mowen dan Minor } \\
\text { (2002:140), Muruganatham } \\
\text { dan Ravi (2013), Dewi dan } \\
\text { Giantari (2015) }\end{array}$ \\
\hline & $\begin{array}{l}\text { Kualitas } \\
\text { Pelayanan } \\
\left(\mathrm{X}_{2}\right)\end{array}$ & $\begin{array}{l}\text { 1) } \\
\text { 2) } \\
\text { 3) } \\
\text { 4) } \\
\text { 5) }\end{array}$ & $\begin{array}{l}\text { Bukti Fisik (Tangibles) } \\
\text { Keandalan (Reliability) } \\
\text { Ketanggapan (Responsiveness) } \\
\text { Jaminan (Assurance) } \\
\text { Empati (Empathy) }\end{array}$ & $\begin{array}{c}\text { Aryadhe dan Rastini (2016), } \\
\text { Parasuraman et al. (1988), } \\
\text { Sulistyawati dan Seminari } \\
\text { (2015) }\end{array}$ \\
\hline \multirow{2}{*}{ Endogen } & $\begin{array}{c}\text { Kepuasan } \\
\text { Pelanggan } \\
\left(\mathrm{Y}_{1}\right)\end{array}$ & $\begin{array}{l}\text { 1) } \\
\text { 2) }\end{array}$ & $\begin{array}{l}\text { Perasaan senang terhadap produk } \\
\text { Kepuasan terhadap keseluruhan } \\
\text { pelayanan yang diberikan } \\
\text { Terpenuhinya harapan pelanggan } \\
\text { setelah membeli produk }\end{array}$ & $\begin{array}{l}\text { Wulandari dan Rahyuda } \\
\text { (2015), Windarti (2012) }\end{array}$ \\
\hline & $\begin{array}{l}\text { Niat Beli } \\
\text { Ulang } \\
\left(\mathrm{Y}_{2}\right)\end{array}$ & 1) & $\begin{array}{l}\text { Adanya kesempatan membeli } \\
\text { kembali } \\
\text { Adanya kemungkinan membeli } \\
\text { kembali } \\
\text { Adanya niat membeli kembali }\end{array}$ & $\begin{array}{c}\text { Chiu et al. (2012), Astarina } \\
\text { dkk. (2017) }\end{array}$ \\
\hline
\end{tabular}

Populasi dalam penelitian ini adalah seluruh pelanggan yang pernah berkunjung dan membeli produk di The Night Market Cafe \& Co Working minimal satu kali. Penelitian ini digunakan metode sampel non probability sampling dengan teknik purposive sampling, dengan jumlah responden sebanyak 150 orang. Metode pengumpulan data dalam penelitian ini adalah metode survei dengan teknik wawancara menggunakan kuisioner.

Jenis data yang digunakan dalam penelitian ini adalah data kualitatif dan data kuantitatif. Sumber data yang digunakan dalam penelitian ini adalah data 
primer. Data primer diperoleh langsung dari sumbernya dengan cara pengumpulan data menggunakan kuisioner.

Instrumen penelitian yang digunakan terdiri atas uji validitas dan uji reliabilitas. Kedua uji tersebut digunakanan agar kuesioner diberikan kepada responded layak untuk digunakan. Validitas dilakukan dengan menghitung korelasi antara skor faktor dengan skor total dan bila korelasi setiap faktor tersebut bernilai positif, maka instrumen penelitian tersebut dapat dikatakan valid. Uji reliabilitas digunakan untuk mengukur konsistensi suatu variabel pada penelitian dari waktu ke waktu.

Penelitian ini menggunakan uji asumsi klasik yang terdiri atas uji normalitas, uji multikolineritas, dan uji heteroskedastisitas, kemudian menggunakan teknik analisis data berupa Path Analysis serta didukung dengan metode pemeriksaan.

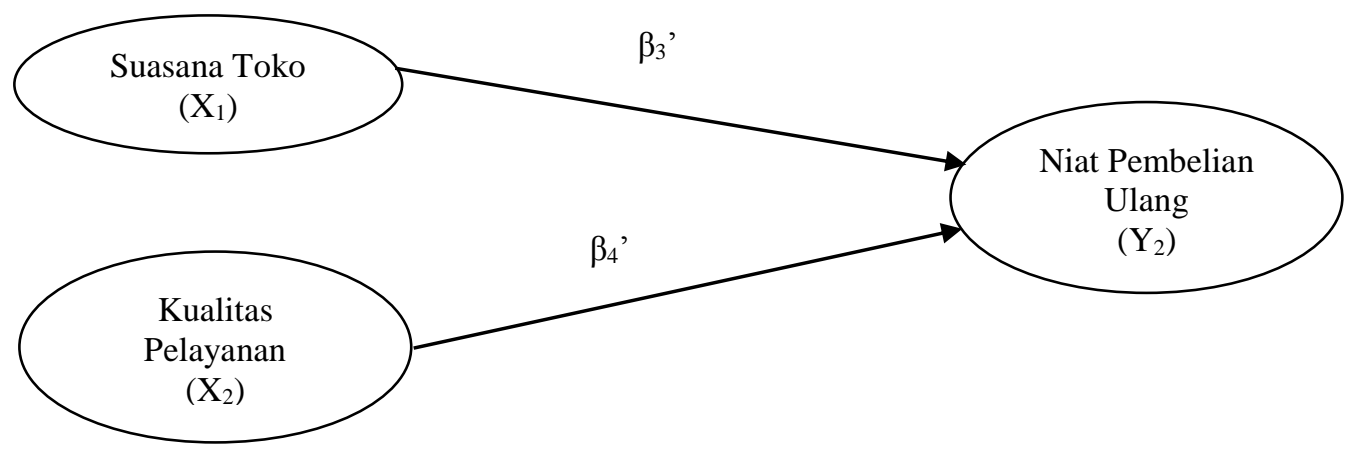

Gambar 2. Model Tanpa Melibatkan Variabel Mediasi

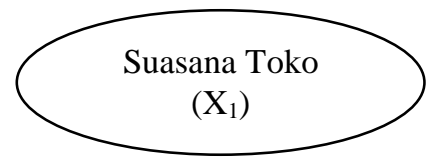

$\beta_{3}$

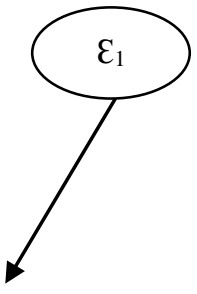

$\varepsilon_{2}$ 1903 


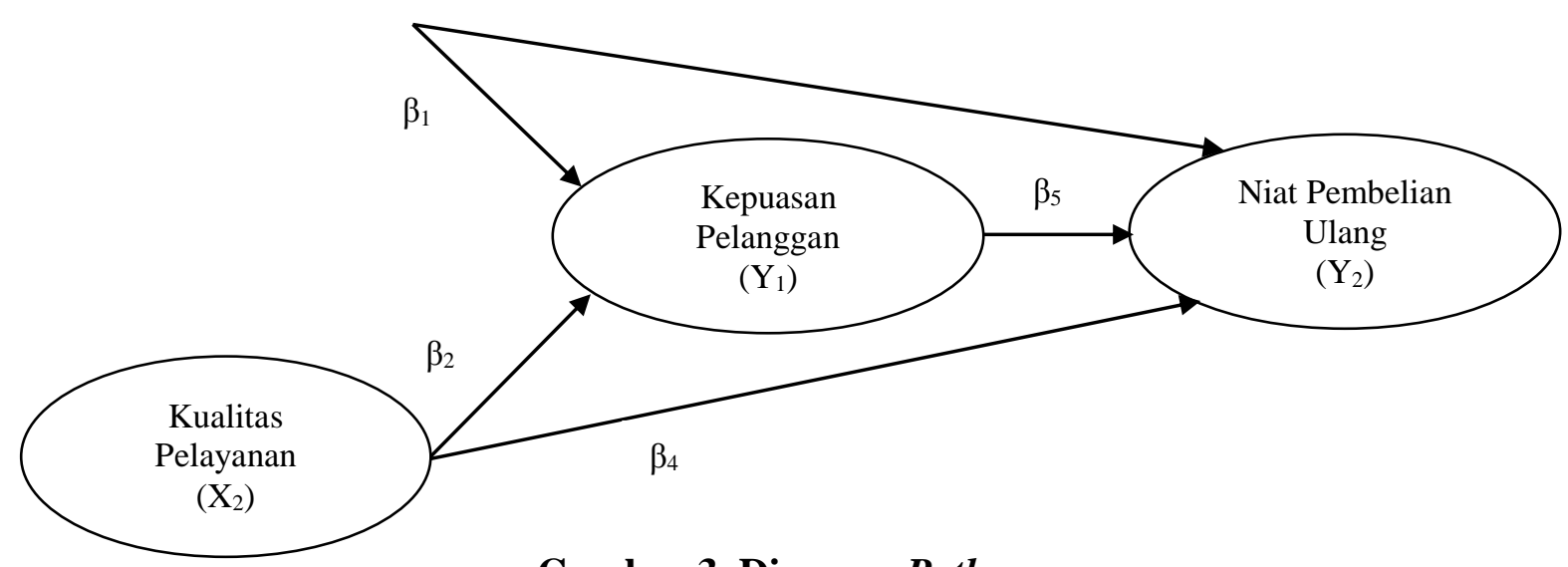

Gambar 3. Diagram Path

Keterangan :

\begin{tabular}{|c|c|}
\hline Y2 & $=$ niat pembelian ulang \\
\hline $\mathrm{X} 1$ & $=$ suasana toko \\
\hline $\mathrm{X} 2$ & $=$ kualitas pelayanan \\
\hline Y1 & $=$ kepuasan pelanggan \\
\hline$\beta 1, \ldots, \beta 5$ & $=$ koefisien regresi variabel \\
\hline & $=$ error \\
\hline
\end{tabular}

\section{HASIL DAN PEMBAHASAN}

Jumlah responden dalam penelitian ini adalah 150 orang. Responden yang memberikan tanggapan untuk kuesioner dari penelitian ini telah memenuhi kriteria-kriteria yang telah ditetapkan dalam kriteria responden penelitian yaitu sudah pernah berkunjung dan membeli produk di The Night Market Cafe \& Co Working minimal satu kali serta berpendidikan minimal SMA/SMK. Responden penelitian dapat dilihat pada tabel karakteristik responden berikut.

Tabel 3.

Karakteristik Responden

\begin{tabular}{ccccc}
\hline No. & Variabel & Klasifikasi & Jumlah (Orang) & Presentase (\%) \\
\hline \multirow{2}{*}{1.} & Usia (tahun) & $19-22$ & 107 & 71 \\
& & $>22-30$ & 28 & 19
\end{tabular}




\begin{tabular}{ccccc} 
& & $>30-52$ & 15 & 10 \\
2. & Jumlah & & 150 & 100 \\
& Jenis Kelamin & Laki-Laki & 48 & 32 \\
& Jumlah & Perempuan & 102 & 68 \\
& & 150 & 100 \\
3. & PNS & 6 & 4 \\
& Pekerjaan & Pegawai Swasta & 29 & 19 \\
& & Mahasiswa & 100 & 67 \\
& Jumlah & Lain-Lain & 15 & 10 \\
\hline
\end{tabular}

Sumber : Data Primer, 2017

Tabel 3 menunjukkan bahwa hasil karakterisitik usia responden dalam kuesioner penelitian memperlihatkan bahwa responden dengan usia terbanyak adalah responden dengan usia 19 - 22 tahun dengan presentase sebesar 71 persen dibandingkan dengan kelompok usia lainnya. Hasil tersebut menunjukkan bahwa pada usia 19 - 22 tahun konsumen lebih cenderung untuk melakukan suatu pembelian di The Night Market Cafe \& Co Working, hal tersebut dikarenakan keinginan yang tinggi untuk mengikuti suatu trend yang sedang marak terjadi serta untuk membeli suatu produk. Penelitian ini juga menunjukkan pembagian berdasarkan hasil karakteristik jenis kelamin yang memperlihatkan bahwa responden dengan jenis kelamin perempuan merupakan responden terbanyak dengan presentase 68 persen.

Berdasarkan hasil karakterisitik pekerjaan responden dalam kuesioner penelitian memperlihatkan bahwa responden dengan pekerjaan mahasiswa merupakan responden terbanyak dengan persentase 67 persen dibandingkan dengan yang lainnya.

Berikut adalah hasil dari analisis jalur dalam penelitian ini yang ditunjukkan oleh Gambar 4 dan Gambar 5 dibawah ini.

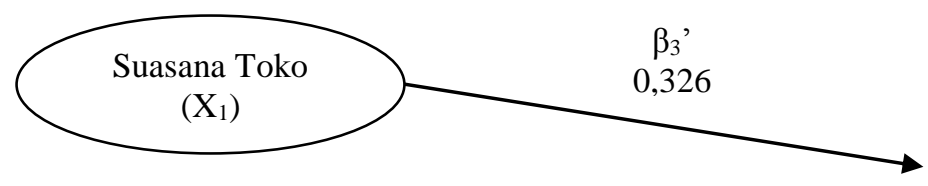




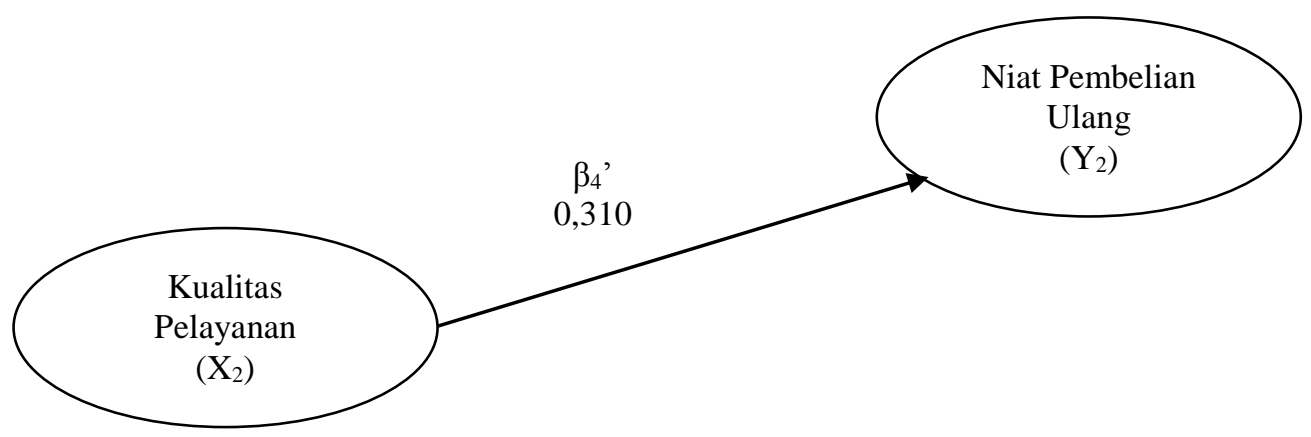

Gambar 4. Validasi Model Analisis Jalur Tanpa Melibatkan Variabel Mediasi

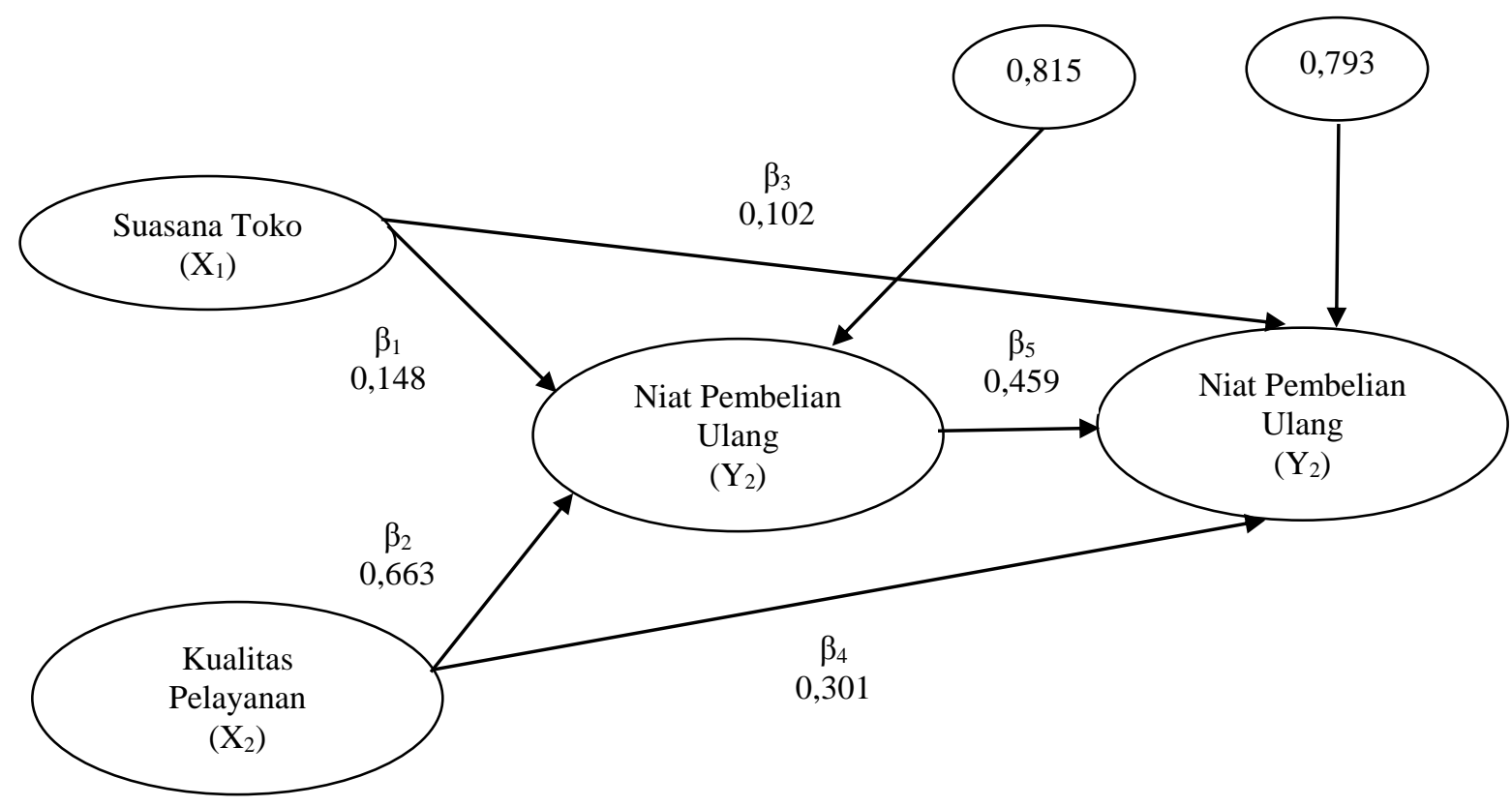

Gambar 5. Validasi Model Diagram Jalur Akhir

Berdasarkan diagram jalur pada Gambar 5 maka dapat dihitung besarnya pengaruh langsung, pengaruh tidak langsung serta pengaruh total antar variabel.

Perhitungan pengaruh antar variabel dirangkum dalam Tabel 4.

Tabel 4. Pengaruh Langsung dan Pengaruh Tidak Langsung serta Pengaruh Total Suasana Toko (X1), Kualitas Pelayanan (X2), Kepuasan Pelanggan (Y1), dan Niat Pembelian Ulang (Y2)

\begin{tabular}{cccc}
\hline $\begin{array}{c}\text { Pengaruh } \\
\text { Variabel }\end{array}$ & $\begin{array}{c}\text { Pengaruh } \\
\text { Langsung }\end{array}$ & $\begin{array}{c}\text { Pengaruh Tidak Langsung } \\
\text { (melalui Kepuasan Pelanggan) }\end{array}$ & $\begin{array}{c}\text { Pengaruh } \\
\text { Total }\end{array}$ \\
\hline $\mathrm{X} 1 \rightarrow \mathrm{Y} 1$ & 0,148 & - & 0,148 \\
$\mathrm{X} 2 \rightarrow \mathrm{Y} 1$ & 0,663 & - & 0,663 \\
\hline
\end{tabular}




\begin{tabular}{cccc}
\hline $\mathrm{X} 1 \rightarrow \mathrm{Y} 2$ & 0,102 & 0,068 & 0,170 \\
$\mathrm{X} 2 \rightarrow \mathrm{Y} 2$ & 0,301 & 0,304 & 0,605 \\
$\mathrm{Y} 1 \rightarrow \mathrm{Y} 2$ & 0,459 & - & 0,459 \\
\hline
\end{tabular}

Sumber : Data Primer (diolah), 2017

Menurut analisis variabel mediasi dengan metode pemeriksaan serta hasil yang didapatkan dari Gambar 4 validasi model analisis jalur tanpa melibatkan variabel mediasi dan Gambar 5 validasi model diagram jalur akhir, maka memenuhi kriteria, yaitu Hasil Analisis, koefesien jalur $\beta 3^{\prime}$ dengan signifikansi sebesar 0,000 dan beta sebesar 0,326 , itu berarti suasana toko berpengaruh signifikan terhadap niat pembelian ulang. Sama halnya dengan koefesien jalur $\beta 4$ ' yang memiliki signifikansi sebesar 0,000 dan beta sebesar 0,310 , itu berarti kualitas pelayanan berpengaruh signifikan terhadap niat pembelian ulang.

Hasil dari $\beta_{1}, \beta_{2}$, dan $\beta_{5}$ signifikan dimana tingkat signifikansi $\beta_{1}$ sebesar 0,029 dan beta sebesar 0,148 , tingkat signifikansi $\beta_{2}$ sebesar 0,000 dan beta sebesar 0,663 , dan tingkat signifikansi $\beta_{5}$ sebesar 0,000 dengan beta sebesar 0,459. Hasil dari $\beta_{3}$ dan $\beta_{4}$ juga signifikan, dimana tingkat signifikansi $\beta_{3}$ sebesar 0,000 dengan beta sebesar 0,102 dan tingkat signifikansi $\beta_{4}$ sebesar 0,000 dengan beta sebesar 0,301 . Hasil koefesien jalur $\beta_{3}$ adalah 0,102 lebih kecil (turun) dari $\beta_{3}$ ' yaitu sebesar 0,326 maka variabel kepuasan pelanggan adalah sebagai variabel mediasi sebagian (partial mediation) pada pengaruh suasana toko terhadap niat pembelian ulang. Hasil koefesien jalur $\beta_{4}$ adalah 0,301 lebih kecil (turun) dari $\beta_{4}$ ' yaitu sebesar 0,310 maka variabel kepuasan pelanggan adalah sebagai variabel 
mediasi sebagian (partial mediation) pada pengaruh kualitas pelayanan terhadap niat pembelian ulang.

Berdasarkan hasil yang diperoleh dapat diketahui bahwa nilai sig. t sebesar 0,029 dengan nilai koefisien beta sebesar 0,148. Nilai sig. t yang menunjukkan nilai $0,029<0,05$, maka dapat disimpulkan terdapat pengaruh yang signifikan antara suasana toko terhadap kepuasan pelanggan. Hasil tersebut menunjukkan bahwa semakin baik suasana toko yang diciptakan maka akan meningkatkan kepuasan pelanggan saat mengunjungi The Night Market Cafe \& Co Working.

Hasil dalam penelitian ini didukung oleh hasil dari penelitian sebelumnya yang dilakukan oleh Tendean (2015) menyatakan bahwa store atmosphere berpengaruh secara positif dan signifikan terhadap kepuasan pelanggan di Maja House Sugar \& Cream Bandung. Begitu juga dengan Tulipa et al. (2014) yang menyatakan bahwa store atmosphere berpengaruh secara positif terhadap kepuasan pelanggan toko grosir di Surabaya. Hal yang serupa dikemukakan oleh Kristiana (2017) bahwa store atmosphere berpengaruh terhadap kepuasan pelanggan Cafe Heerlijk Gelato Perpustakaan Bank Indonesia Surabaya.

Berdasarkan hasil yang diperoleh dapat diketahui bahwa nilai sig. t sebesar 0,000 dengan nilai koefisien beta sebesar 0,663. Nilai sig. $\mathrm{t}$ yang menunjukkan nilai $0,000<0,05$, maka dapat disimpulkan terdapat pengaruh yang signifikan antara kualitas pelayanan terhadap kepuasan pelanggan. Hasil tersebut menunjukkan bahwa semakin baik kualitas pelayanan yang diberikan maka akan meningkatkan kepuasan pelanggan saat mengunjungi The Night Market Cafe \& Co Working. 
Hasil dalam penelitian ini didukung oleh hasil dari penelitian sebelumnya yang dilakukan oleh Heryani (2014) menyatakan bahwa terdapat pengaruh yang positif dan signifikan antara kualitas pelayanan terhadap kepuasan pelanggan di Bengkel Andoyo Motor Yogyakarta. Selaras dengan penelitian yang dilakukan oleh Yunus (2014) yang menyatakan bahwa terdapat pengaruh secara positif dan signifikan dari variabel kualitas pelayanan terhadap variabel kepuasan pelanggan. Hal ini didukung pula oleh hasil penelitian Budiarti (2013) yang menyatakan bahwa variabel kualitas pelayanan berpengaruh secara langsung terhadap kepuasan pelanggan di counter The Body Shop Malioboro Mall Yogyakarta.

Berdasarkan hasil yang diperoleh dapat diketahui bahwa nilai sig. t sebesar 0,027 dengan nilai koefisien beta sebesar 0,102. Nilai sig. t yang menunjukkan nilai $0,000<0,05$, maka dapat disimpulkan terdapat pengaruh yang signifikan antara kualitas pelayanan terhadap kepuasan pelanggan. Hasil tersebut menunjukkan bahwa semakin baik suasana toko yang diciptakan maka akan meningkatkan niat pembelian ulang di The Night Market Cafe \& Co Working.

Hasil dalam penelitian ini didukung oleh hasil dari penelitian sebelumnya yang dilakukan oleh Angger dan Rubiyanti (2015) menyatakan bahwa store atmosphere berpengaruh secara signifikan terhadap minat pembelian ulang pada Jigoku Ramen Bandung. Tulipa et al. (2014) juga menyatakan bahwa store atmosphere berpengaruh secara positif terhadap niat beli ulang (repurchase intention) pada pelanggan toko grosir di Surabaya. Hal yang sama juga di kemukakan oleh Triani (2013) bahwa suasana toko berpengaruh positif terhadap niat beli ulang pelanggannya pada Indogrosir Palembang. 
Berdasarkan hasil yang diperoleh dapat diketahui bahwa nilai sig. t sebesar 0,000 dengan nilai koefisien beta sebesar 0,301 . Nilai sig. t yang menunjukkan nilai $0,000<0,05$, maka dapat disimpulkan terdapat pengaruh yang signifikan antara kualitas pelayanan terhadap niat pembelian ulang. Hasil tersebut menunjukkan bahwa semakin baik kualitas pelayanan yang diberikan maka akan meningkatkan niat pembelian ulang di The Night Market Cafe \& Co Working.

Hasil dalam penelitian ini didukung oleh hasil dari penelitian sebelumnya yang dilakukan oleh Rizqulloh (2015) menyatakan bahwa kualitas pelayanan berpengaruh positif dan signifikan terhadap niat pembelian kembali pada bukalapak.com. Hal yang sama juga diungkapkan oleh Aryadhe dan Rastini (2016) bahwa kualitas pelayanan berpengaruh positif dan signifikan terhadap niat pembelian kembali pada PT Agung Toyota Denpasar. Adixio dan Saleh (2013) juga menyatakan bahwa kualitas pelayanan berpengaruh signifikan positif terhadap niat pembelian ulang pada pelanggan Restoran Solaria di Surabaya.

Berdasarkan hasil yang diperoleh dapat diketahui bahwa nilai sig. t sebesar 0,000 dengan nilai koefisien beta sebesar 0,459. Nilai sig. t yang menunjukkan nilai $0,000<0,05$, maka dapat disimpulkan terdapat pengaruh yang signifikan antara kepuasan pelanggan terhadap niat pembelian ulang. Hasil tersebut menunjukkan bahwa semakin tinggi kepuasan yang dirasakan oleh pelanggan maka akan meningkatkan niat pembelian ulang di The Night Market Cafe \& Co Working.

Hasil dalam penelitian ini didukung oleh hasil dari penelitian sebelumnya yang dilakukan oleh Puspitasari (2011) mengemukakan bahwa kepuasan 
pelanggan berpengaruh signifikan dalam meningkatkan niat beli ulang Nokia di Semarang. Palma dan Andjarwati (2016) juga menyatakan bahwa terdapat pengaruh yang signifikan dari kepuasan pelanggan terhadap niat beli ulang pada pelanggan produk fashion di toko online di Surabaya. Hal tersebut didukung pula oleh penelitian Yan et al. (2015) bahwa kepuasan pelanggan secara positif dan signifikan mempengaruhi niat pembelian kembali di restoran di China.

Berdasarkan hasil yang diperoleh dengan melihat validasi model analisis jalur tanpa melibatkan variabel mediasi dan validasi model diagram jalur akhir yang berpatokan pada teori Solimun, membuktikan bahwa hasil koefesien jalur $\beta_{3}$ adalah 0,102 lebih kecil (turun) dari $\beta_{3}$ ' yaitu sebesar 0,326 maka variabel kepuasan pelanggan adalah sebagai variabel mediasi sebagian (partial mediation) pada pengaruh suasana toko terhadap niat pembelian ulang. Hasil tersebut menunjukkan hasil yang positif dan signifikan, yang mengindikasikan bahwa dengan adanya suasana toko yang menarik akan meningkatkan kepuasan pelanggan sehingga secara otomatis akan meningkatkan niat pembelian ulang pada The Night Market Cafe \& Co Working.

Hasil dalam penelitian ini didukung oleh hasil dari penelitian sebelumnya yang dilakukan oleh Heryani (2014) menyatakan bahwa semakin tinggi atau semakin nyaman store atmosphere yang diberikan bengkel Andoyo Motor kepada pelanggan akan memberikan kepuasan kepada pelanggan dan akan meningkatkan pembelian ulang di bengkel Andoyo Motor.

Berdasarkan hasil yang diperoleh dengan melihat validasi model analisis jalur tanpa melibatkan variabel mediasi dan validasi model diagram jalur akhir 
yang berpatokan pada teori Solimun, membuktikan bahwa hasil koefesien jalur $\beta_{4}$ adalah 0,301 lebih kecil (turun) dari $\beta_{4}$ ' yaitu sebesar 0,310 maka variabel kepuasan pelanggan adalah sebagai variabel mediasi sebagian (partial mediation) pada pengaruh kualitas pelayanan terhadap niat pembelian ulang. Hasil tersebut menunjukkan hasil yang positif dan signifikan, yang mengindikasikan bahwa dengan adanya kualitas pelayanan yang baik akan meningkatkan kepuasan pelanggan sehingga secara otomatis akan meningkatkan niat pembelian ulang pada The Night Market Cafe \& Co Working.

Hasil dalam penelitian ini tidak didukung oleh hasil dari penelitian sebelumnya yang dilakukan oleh Adixio dan Saleh (2013) menyatakan bahwa kualitas pelayanan berpengaruh signifikan positif terhadap niat pembelian ulang melalui mediasi kepuasan pelanggan pada restoran Solaria di Surabaya. Selaras pula oleh Heryani (2014) yang menyatakan bahwa semakin tinggi kualitas pelayanan yang diberikan bengkel Andoyo Motor akan memberikan kepuasan pelanggan dan kepuasan pelanggan yang dihasilkan akan meningkatkan pembelian ulang di bengkel Andoyo Motor.

\section{SIMPULAN DAN SARAN}

Berdasarkan hasil pembahasan, dapat ditarik beberapa simpulan antara lain suasana toko berpengaruh positif dan signifikan terhadap kepuasan pelanggan pada The Night Market Cafe \& Co Working di Denpasar. Hasil penelitian ini membuktikan bahwa semakin baik dan menarik suasana toko yang diciptakan maka akan menimbulkan kepuasan pada para pelanggan; kualitas pelayanan 
berpengaruh positif dan signifikan terhadap kepuasan pelanggan pada The Night Market Cafe \& Co Working di Denpasar. Hasil penelitian ini membuktikan bahwa jika kualitas pelayanan yang baik akan menimbulkan kepuasan pada para pelanggan; suasana toko berpengaruh positif dan signifikan terhadap niat pembelian ulang pada The Night Market Cafe \& Co Working di Denpasar. Hasil penelitian ini membuktikan bahwa semakin baik dan menarik suasana toko yang diciptakan maka niat pembelian ulang para pelanggan akan meningkat; kualitas pelayanan berpengaruh positif dan signifikan terhadap niat pembelian ulang pada The Night Market Cafe \& Co Working di Denpasar. Hasil penelitian ini membuktikan bahwa jika kualitas pelayanan yang baik maka niat pembelian ulang para pelanggan akan meningkat; kepuasan pelanggan berpengaruh positif dan signifikan terhadap niat pembelian ulang pada The Night Market Cafe \& Co Working di Denpasar. Hasil penelitian ini membuktikan bahwa jika kepuasan pelanggan akan meningkatkan maka niat pembelian ulang para pelanggan; kepuasan pelanggan berpengaruh positif dan signifikan dalam memediasi pengaruh suasana toko terhadap niat pembelian ulang pada The Night Market Cafe \& Co Working di Denpasar. Hasil tersebut membuktikan bahwa dengan adanya suasana toko yang menarik akan meningkatkan kepuasan pelanggan sehingga secara otomatis akan meningkatkan niat pembelian ulang; kepuasan pelanggan berpengaruh positif dan signifikan dalam memediasi pengaruh kualitas pelayanan terhadap niat pembelian ulang pada The Night Market Cafe \& Co Working di Denpasar. Hasil tersebut membuktikan bahwa dengan adanya kualitas 
pelayanan yang baik akan meningkatkan kepuasan pelanggan sehingga secara otomatis akan meningkatkan niat pembelian ulang.

Berdasarkan hasil analisis dan simpulan, maka saran yang dapat diberikan kepada pihak-pihak yang memerlukan antara lain yaitu The Night Market Cafe \& Co Working sebaiknya lebih memperhatikan kondisi suasana toko maupun lingkungan di sekitarnya, seperti penggunaan variasi warna dalam toko, musik yang diputar dalam toko, aksesoris atau furniture yang dapat menarik minat konsumen serta lahan parkir yang memadai sehingga pelanggan akan merasa lebih nyaman saat berkunjung dan menikmati hidangan di The Night Market Cafe \& Co Working, dengan begitu akan dapat meningkatkan niat pembelian ulang oleh pelanggan; selain itu The Night Market Cafe \& Co Working sebaiknya memperhatikan kualitas pelayanan yang diberikan, dimulai dari cita rasa hidangan, bentuk serta cara penyajian, hingga kesopanan dan keramahan dari karyawan The Night Market Cafe \& Co Working itu sendiri. Ketika pelanggan merasa puas dengan pelayanan yang diberikan maka akan dapat meningkatkan niat pembelian ulang; bagi peneliti selanjutnya hendaknya dapat mengembangkan penelitian ini dengan nantinya mengacu pada keterbatasan penelitian yang telah disampaikan sebelumnya dan memasukkan faktor-faktor lain yang dirasa turut memediasi atau mempengaruhi hubungan dari variabel-variabel yang digunakan dalam penelitian ini serta diharapkan mampu menambah referensi terhadap variabel yang akan diteliti.

Implikasi hasil penelitian yang diperoleh, yaitu pertama, terbukti bahwa responden melihat suasana toko yang unik pada The Night Market Cafe \& Co 
Working. Pernyataan responden tentang desain bangunan diindikasikan bahwa pelanggan merasa desain bangunan yang diciptakan oleh The Night Market Cafe \& Co Working mampu menarik minat pelanggan untuk mengunjungi The Night Market Cafe \& Co Working. Melihat hal ini maka penting bagi owner untuk lebih memperhatikan dan menjaga desain bangunan yang sudah ada, bahkan akan lebih baik apabila dilakukan inovasi atau perbaharuan dari desain bangunan sebelumnya guna meningkatkan niat pembelian ulang pelanggan untuk mengunjungi The Night Market Cafe \& Co Working

Implikasi kedua yang dapat diambil dari penelitian ini selanjutnya adalah kualitas pelayanan dari The Night Market Cafe \& Co Working. Pernyataan yang menyatakan "The Night Market Cafe \& Co Working di Denpasar nyaman" mendapat skor tertinggi dari pernyataan lainnya, hal ini menandakan bahwa pelanggan telah merasakan The Night Market Cafe \& Co Working sudah memberikan pelayanan yang terbaik. Melihat hal ini maka sangatlah penting bagi owner untuk selalu memperhatikan dan meningkatkan kualitas pelayanannya sehingga pelanggan selalu merasa nyaman dan puas.

Implikasi selanjutnya dalam penelitian ini menunjukkan bahwa responden memiliki rasa puas setelah mengunjungi The Night Market Cafe \& Co Working. Melihat hal ini diharapkan owner mampu mempertahankan bahkan lebih meningkatkan kinerja serta kualitas yang ada saat ini sehingga dapat terus menjalin hubungan yang positif dengan pelanggan.

Terakhir, dalam penelitian ini terlihat bahwa responden memiliki keinginan untuk melakukan pembelian kembali di The Night Market Cafe \& Co Working. 
Maka dapat disarankan bagi owner dalam hal pentingnya berinovasi disegala aspek dan memperhatikan perubahan yang ada di lingkungan sekitar agar dapat terus memenuhi keinginan para pelanggannya. Ketika pelanggan merasa apa yang ia butuhkan terpenuhi maka pelanggan akan meras puas dan cenderung memiliki niat untuk melakukan pembelian ulang.

Beberapa keterbatasan dalam penelitian ini adalah ruang lingkup penelitian ini terbatas pada pengunjung yang pernah berkunjung ke The Night Market Cafe \& Co Working di Denpasar, sehingga hasil penelitian ini tidak bisa digeneralisir; selain itu mengingat penelitian ini dilakukan dalam jangka waktu yang relatif singkat sedangkan lingkungan, trend dan kebiasaan dapat berubah setiap saat, yang menyebabkan penelitian ini penting untuk dilakukan kembali.

\section{REFERENSI}

Adixio, Riko Firmawan dan Laila Saleh. 2013. Pengaruh Kualitas Layanan Dan Nilai Yang Dirasakan Terhadap Niat Pembelian Ulang Melalui Mediasi Kepuasan Pelanggan Restoran Solaria Di Surabaya. Journal of Business and Banking, 3 (2), 151-164.

Allameh, Sayyed Mohsen, Javad Khazaei Pool, Akbar Jaberi, Reza Salehzadeh, and Hassan Asadi. 2015. Factors influencing sport tourists' revisit intentions. Asia Pacific Journal of Marketing and Logistics, 27 (2), 191207.

Angger, Panuntun Setyo dan Rubiyanti Nurfani. 2015. Pengaruh Atmosphere Terhadap Minat Pembelian Ulang Pada Jigoku Ramen Bandung. $e$ Proceeding of Management Universitas Telkom, 2 (1), 1-6.

Aryadhe, Pebriana dan Ni Made Rastini. 2016. Kualitas Pelayanan, Kualitas Produk Dan Citra Merek Terhadap Niat Beli Ulang Di Pt Agung Toyota Denpasar. E-Jurnal Manajemen Unud, 5 (9), 5695-5721.

Astarina, I Gusti Ayu, I Gusti Ayu Ketut Giantari, dan Ni Nyoman Kerti Yasa. 2017. Peran Kepercayaan Memediasi Pengaruh Pengalaman Terhadap Niat Menggunakan Kembali Jasa Go-Jek Di Kota Denpasar. E-Jurnal Manajemen Unud, 6 (5), 2308-2334. 
Berman, Barry dan Evans, Joel.R. 2007. Retail Management. 10th. ed. United Stated of Amerika: Pearson Prentice Hall .

Budiarti, Fransisca Eka. 2013. Pengaruh Kualitas Produk, Kualitas Layanan Dan Kepuasan Konsumen Terhadap Pembelian Ulang (Studi Kasus pada Counter The Body Shop Malioboro Mall Yogyakarta). Skripsi, Sarjana Jurusan Manajemen Fakultas Ekonomi Universitas Sanata Dharma Yogyakarta, Yogyakarta.

Chiu, C.M., Hsu, M.H., Lai, H., dan Chang, C.M. 2012. Re-Examining The Influence of Trust on Online Repeat Purchase Intention: The Moderating Role Of Habit And Its Antecedents. Decision Support System, 53 (4), 835845.

Destanti, Retno Ayu. 2010. Pengaruh Kualitas Layanan Terhadap Kepuasan Dan Loyalitas Pelanggan Pada Jasa Salon Dan Internet Service Provider Di Yogyakarta. Skripsi, Jurusan Manajemen Fakultas Ekonomi, UAJY.

Dewi, Kade Trisna, dan I Gusti Ayu Ketut Giantari. 2015. Peran Emosi Positif Dalam Memediasi Store Atmosphere Terhadap Pembelian Impulsif. EJurnal Manajemen Unud, 4 (12), 4419-4448.

Ekinci, Yuksel, Philip L. Dawes, dan Graham R. Massey. 2008. An extended model of the antecedents and consequences of consumer satisfaction for hospitality services. European Journal of Marketing, 42 (1), 35-68.

Faradiba, Sri Rahayu Tri Astuti. 2013. Analisis Pengaruh Kualitas Produk, Harga, Lokasi Dan Kualitas Pelayanan Terhadap Minat Beli Ulang Konsumen. Diponegoro Journal Of Management, 2 (3), hal.1-11

Faradisa, Isti, Leonardo Budi H, dan Maria M. Minarsih. 2016. Analisis Pengaruh Variasi Produk, Fasilitas, Dan Kualitas Pelayanan Terhadap Minat Beli Ulang Konsumen Pada Indonesian Coffeeshop Semarang (Icos Café). Journal Of Management, 2 (2), hal.1-13

Gonius, Natalia. 2013. Studi Deskriptif Tentang Customer Complaints di Restoran Wok Noodles Di Galaxy Mall Surabaya. Jurnal Ilmiah Mahasiswa Universitas Surabaya, 2 (1), hal.1-15

Heryani, Yukhebeth Yulita. 2014. Pengaruh Kualitas Pelayanan Dan Store Atmosphere Terhadap Pembelian Ulang Yang Dimediasi Oleh Kepuasan Konsumen (Studi Pada Konsumen Bengkel Andoyo Motor Yogyakarta). Skripsi, Sarjana Jurusan Manajemen Fakultas Ekonomi Universitas Negeri Yogyakarta, Yogyakarta

Heung, Vincent C.S. and $\mathrm{Gu}$ Tianming. 2012. Influence of Restaurant Atmospherics On Patron Satisfaction And Behavioral Intention. International Journal of Hospitality Management, 31, 1167-1177. 
Hussain, Riaz and Mazhar Ali. 2015. Effect of Store Atmosphere on Consumer Purchase Intention. International Journal of Marketing Studies, 7 (2), 3543.

Kotler, $\mathrm{P}$ and Armstrong. 2010. Principles of Marketing, thirteen edition. New Jersey: Prentice-Hall, Inc.

Kotler, Philip and Keller, Kevin. 2012. Manajemen Pemasaran. Edisi 14. Jakarta: Erlangga.

Kristiana, Maria dan Muhammad Edwar. 2017. Pengaruh Store Atmosphere Dan Kualitas Layanan Terhadap Kepuasan Konsumen Cafe Heerlijk Gelato Perpustakaan Bank Indonesia Surabaya. Jurnal Pendidikan Tata Niaga (JPTN), 1 (1), 113-117.

Marinkovic, Veljko, Vladimir Senic, Danijela Ivkov, Darko Dimitrovski, and Marija Bjelic. 2014. The antecedents of satisfaction revisit intentions for full-service restaurants. Marketing Intelligence \& Planning, 32 (3), 311327.

Mowen, Jhon C. and Michael Minor. 2002. Perilaku Konsumen. Jilid Kedua. Alih Bahasa: Dwi Kartini. Jakarta: Erlangga.

Muruganatham, G., and Ravi Shankar Bakat. 2013. A Review of Impulse Buying Behaviour. International Journal of Marketing Studies, 3(3), hal.78-88

Palma, Marisa Arnindita dan Andjarwati, Anik Lestari. 2016. Pengaruh Kualitas Produk, Kemudahan, Dan Harga Terhadap Niat Beli Ulang Dengan Kepuasan Sebagai Variabel Intervening. Journal of Research In Economics And Management, 16 (1), 84-104.

Parasuraman, Valarie A. Zeithaml, dan Leonard L. Berry. 1988. SERVQUAL:A Multiple-Item Scale for Measuring Consumer Perceptions of Service Quality. Journal of Retailing, 64 (1), 12-40.

Pratminingsih, Sri Astuti, Christina Lipuringtyas Rudatin, dan Tetty Rimenta. 2014. Roles of Motivation and Destination Image in Predicting Tourist Revisit Intention: A Case of Bandung - Indonesia. International Journal of Innovation, Management and Technology, 5 (1), hal.19-24

Qin, Hong. and Victor. R. Prybutok. 2009. Service Quality, Customer Satisfaction, and Behavioral Intention In Fast Food Restaurant. International Journal of Quality and Service Serences, 1 (1), 78-95.

Rizqulloh, Firza dan Tety Elida. 2015. Pengaruh Kualitas Pelayanan, Word Of Mouth, Dan Loyalitas Pelanggan Terhadap Niat Pembelian Kembali Pada Bukalapak.Com. Jurnal Ilmiah Ekonomi Bisnis, 20 (2), 113-120.

Seni'c, Vladimir and Veljko Marinkovi'c. 2013. Patient care, satisfaction and service quality in health care. International Journal of Consumer Studies, 37 (3), 312-319. 
Sinaga, Inggrid., Suharyono., dan Srikandi Kumadji. 2012. Stimulus Store Environment dalam Menciptakan Emotional Response dan Pengaruhnya Terhadap Impulse Buying. Jurnal Profit, 6 (2), 1-14.

Solimun, Adji Achmad Rinaldo Fernandes, dan Nuriannah. 2017. Metode Statistika Multivariat Pemodelan Persamaan Struktural (SEM) Pendekatan WarpPLS. Malang : UB Press.

Suaridewi, I.G.A. Ayu Mas. 2016. Peran Perceived Value Memediasi Pengaruh Kualitas Pelayanan Terhadap Kepuasan Konsumen (Studi Pada Konsumen Kedai Cafeetory di Kota Denpasar). Skripsi, Sarjana Jurusan Manajemen Fakultas Ekonomi dan Bisnis Universitas Udayana, Denpasar.

Sulistyawati, Ni Made Ari, dan Ni Ketut Seminari. 2015. Pengaruh Kualitas Pelayanan Terhadap Kepuasan Pelanggan Restoran Indus Ubud Gianyar. E-Jurnal Manajemen Unud, 4 (8), 2318-2332.

Tendean, Andi dan Arry Widodo. 2015. Pengaruh Store Atmosphere Terhadap Kepuasan Konsumen. e-Proceeding of Management Universitas Telkom.

Triani, Evilia. 2013. Pengaruh Suasana Toko dan Lokasi terhadap Minat Beli Konsumen Pada Indogrosir Palembang. Skripsi.

Tu, Chien-Chung, Kwoting Fang, and Chwen-Yea Lin. 2012. Perceived Ease of Use, Trust, and Satisfaction as Determinants of Loyalty in e-Auction Marketplace. Journal of Computers, 7 (3), 645-652.

Tulipa, Diyah, Sri Gunawan, dan V. Henky Supit. 2014. The Influence of Store Atmosphere on Emotional Responses and Re-Purchase Intentions. Business Management and Strategy, 5 (2), 151-164.

Windarti, Gst. Ayu Oka. 2012. Pengaruh Kualitas Pelayanan Jasa Terhadap Kepuasan Nasabah Pada PT. Bank Negara Indonesia (Persero) Tbk Kantor Cabang Utama (KCU) Palembang. Jurnal Ekonomi dan Informasi Akuntansi, 2 (1), 1-20.

Wulandari, Hesti, dan I Ketut Rahyuda. 2016. Peran Kepuasan Pelanggan Memediasi Harga Dan Loyalitas Pelanggan. E-Jurnal Manajemen Unud, 5 (5), 2871-2897.

Yan, Xiangbin, Jing Wang, and Michael Chau. 2015. Customer revisit intention to restaurants: Evidence from online reviews. Inf Syst Front, 17, 645-657.

Yunus dan Budianto. 2014. Pengaruh Kualitas Pelayanan Dan Fasilitas Terhadap Kepuasan Pelanggan. Jurnal Ilmu \& Riset Manajemen, 3 (12), 1-20. 